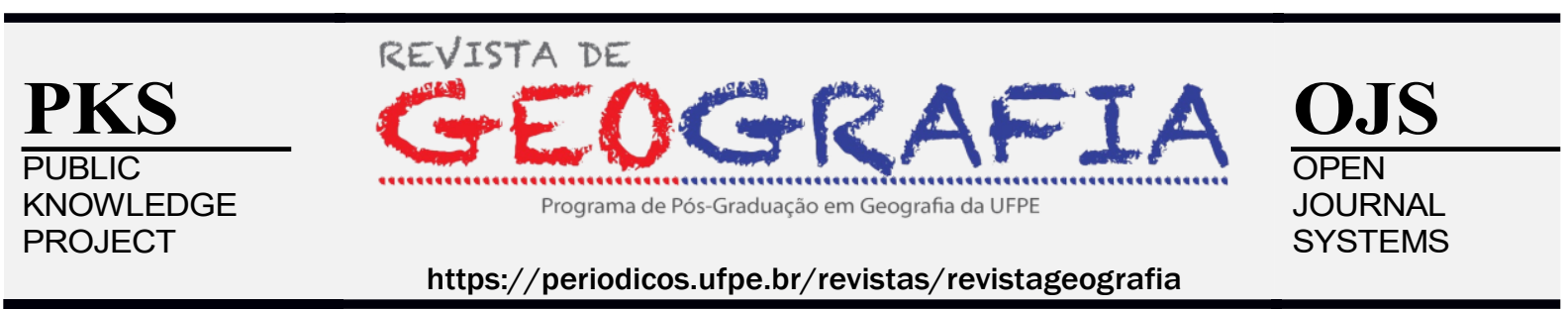

\title{
MOBILIDADE DO TRABALHO CAMPONÊS EM ITABAIANA/SERGIPE
}

\author{
Juliana Lima da $\operatorname{Costa}^{1}$, Marleide Maria Santos Sergio ${ }^{2}$ \\ ${ }^{1}$ Mestranda em Geografia pelo Programa de Pós Graduação em Geografia da Universidade Federal de Sergipe. \\ Linha de Pesquisa: Produção e Organização do Espaço Agrário, E-mail: julliana.limatvd@gmail.com, Orcid: \\ http://orcid.org/0000-0001-7518-3700 \\ ${ }^{2}$ Doutorado em Geografia pela Universidade Federal de Sergipe, onde atua como professora adjunta no Depto. \\ de Geografia do Campus Professor Alberto Carvalho e do Programa de Pós-Graduação em Geografia, E-mail: \\ marleidesergio@gmail.com, Orcid: http://orcid.org/0000-0001-8984-1671
}

Artigo recebido em 01/08/2021 e aceito em 18/09/2021

\section{RESUMO}

Este escrito visa analisar a mobilidade do trabalho camponês no munícipio de Itabaiana/SE. O munícipio, localizado no Agreste Sergipano, é reconhecido como um "celeiro agrícola". Mas, apesar de forte base agrícola, atualmente o município se caracteriza como predominantemente urbano, pois $77 \%$ de sua população reside na cidade. Seguindo uma tendência mundial, a população rural vem decrescendo, resultando no esvaziamento do campo e inchaço urbano. Em Itabaiana, nota-se que muitos dos camponeses que migram para a cidade não se desfazem de suas terras e continuam a trabalhar em seus sítios. Com o avanço do capitalismo verifica-se a consolidação da propriedade privada e a submissão cada vez maior dos indivíduos aos seus ditames. Dessa forma a sociedade molda-se seguindo sua lógica, produzindo espaços que garantam e intensifiquem a acumulação de capital. A mobilidade do trabalho é introduzida no modo de produção capitalista, como a condição de exercício da liberdade de se deixar sujeitar ao Capital. No entanto, a mobilidade do trabalho camponês nesse trabalho é analisada como uma forma de resistência, visto que os camponeses mesmo residindo na cidade, continuam a trabalhar nos seus sítios reproduzindo seu modo de vida na terra. Para atingir o objetivo do texto fez-se necessário a realização de levantamentos bibliográficos e trabalhos de campo. Por fim, compreendemos a necessidade de observar e entender esse processo a partir das próprias contradições do desenvolvimento capitalista.

Palavras-chave: mobilidade do trabalho; campesinato; esvaziamento do campo; Itabaiana.

\section{MOBILITY OF PEASANT LABOR IN ITABAIANA/SERGIPE}

\section{ABSTRACT}

This paper objective to analyze the mobility of peasant labor in the municipality of Itabaiana/SE. The municipality, located in Agreste Sergipano, is recognized as an "agricultural barn". However, despite its strong agricultural base, the municipality is currently characterized as predominantly urban, as $77 \%$ of its population resides in the city. Following a worldwide trend, the rural population has been decreasing, resulting in the emptying of the countryside and urban swelling. In Itabaiana, it is noted that many of the peasants who migrate to the city do not give up their land and continue to work on their farms. With the advance of capitalism, there is a consolidation of private property and an increasing submission of 
individuals to its dictates. In this way, society shapes itself following its logic, producing spaces that guarantee and intensify the accumulation of capital. Labor mobility is introduced in the capitalist mode of production, as the condition for exercising the freedom to be subject to Capital. However, the mobility of peasant labor in this work is analyzed as a form of resistance, since peasants, even living in the city, continue to work on their farms, reproducing their way of life on the land. To achieve the objective of the text, it was necessary to carry out bibliographic surveys and fieldwork. Finally, we understand the need to observe and understand this process from the very contradictions of capitalist development

Keywords: labor mobility; peasant; countryside emptying; Itabaiana

\section{MOVILIDAD DEL TRABAJO CAMPESINO EN ITABAIANA/SERGIPE}

\section{RESUMEN}

Este trabajo tiene como objetivo analizar la movilidad de la mano de obra campesina en el municipio de Itabaiana / SE. El municipio, ubicado en Agreste Sergipano, está reconocido como "granero agrícola". Sin embargo, a pesar de su fuerte base agrícola, el municipio se caracteriza actualmente por ser predominantemente urbano, ya que el $77 \%$ de su población reside en la ciudad. Siguiendo una tendencia mundial, la población rural ha ido disminuyendo, lo que ha provocado el vaciamiento del campo y la expansión urbana. En Itabaiana, se observa que muchos de los campesinos que migran a la ciudad no ceden sus tierras y continúan trabajando en sus fincas. Con el avance del capitalismo, hay una consolidación de la propiedad privada y una creciente sumisión de los individuos a sus dictados. De esta forma, la sociedad se configura siguiendo su lógica, produciendo espacios que garantizan e intensifican la acumulación de capital. La movilidad laboral se introduce en el modo de producción capitalista, como condición para ejercer la libertad de estar sujeto al Capital. Sin embargo, la movilidad de la mano de obra campesina en este trabajo se analiza como una forma de resistencia, ya que los campesinos, aun viviendo en la ciudad, continúan trabajando en sus fincas, reproduciendo su forma de vida en la tierra. Para lograr el objetivo del texto fue necesario realizar estudios bibliográficos y trabajo de campo. Finalmente, entendemos la necesidad de observar y comprender este proceso desde las mismas contradicciones del desarrollo capitalista.

Palavras clave: movilidad del trabajo; campesinado; vaciado de campo; Itabaiana.

\section{INTRODUÇÃO}

O fim da hegemonia agrário-exportadora no Brasil e o início da predominância da estrutura produtiva urbano-industrial acontece após a revolução de 1930. Como analisa Oliveira (2003), apesar de ter se iniciado as mudanças na base produtiva após 1930, o modelo urbanoindustrial só se concretiza em 1956, quando pela primeira vez a participação da indústria na renda interna supera a da agricultura. Dentre os fatores que contribuíram para esse novo processo de acumulação estão as novas correlações de forças sociais, a reformulação do aparelho e da ação estatal e a regulamentação das leis trabalhistas (OLIVEIRA, 2003).

A partir dessa dinâmica, têm-se a aceleração dos processos de urbanização e de produção de cidades. Logo a população que migrava para as cidades necessitava ser 
transformada em exército de reserva, fator necessário do ponto de vista do modo de acumulação que se iniciava. Como assinala Oliveira, 2003, p. 38:

De um lado o exército de reserva propiciava o horizonte médio para o cálculo econômico empresarial, liberto do pesadelo de um mercado de concorrência perfeita, no qual ele devesse competir pelo uso dos fatores; de outro lado a legislação trabalhista igualava reduzindo - antes que incrementando - o preço da força de trabalho.

A formação de um exército de reserva fazia parte de uma perspectiva de desenvolvimento consolidada a partir dos anos 1950, referendada, de acordo com Delgado (1985), no discurso conservador de que a agricultura poderia cumprir as funções clássicas para o desenvolvimento econômico do Brasil, prescindindo de reformas estruturais. Uma dessas funções era justamente liberar mão-de-obra para o setor industrial.

Dessa forma a população passa a migrar para as cidades, que passam a ser sinônimo do progresso, esvaziando o campo. Na cidade tornam-se trabalhadores em busca de emprego para se reincluírem na sociedade (MARTINS, 2002). O autor chama a atenção para uma nova forma de exclusão/inclusão, cada vez mais comum posta hoje, na sociedade capitalista aos chamados excluídos que está nas formas crescentemente perversas de inclusão, na degradação da pessoa e na desvalorização do trabalho como meio de inserção digna na sociedade.

Partindo do princípio que uma das questões mais proeminentes do funcionamento do modo de produção capitalista é a forma pela qual o capital assume seu ímpeto por acumular, é preciso pensarmos o capital como o causador do descarte em massa de trabalhadores do processo produtivo (JAKIMIU; GEMELLI, 2015). Nesse contexto o desemprego é uma realidade crescente, que forçadamente obriga o trabalhador a migrar, produzindo o fenômeno da mobilidade do trabalho, que trata das formas como o capital produz, explora, faz circular e controla, tanto pelo lado da oferta como pela demanda, a força de trabalho como mercadoria essencial ao processo de acumulação capitalista.

Mas este modo de produção possui diversas contradições que são inerentes ao próprio sistema. Mesmo com a tendência de esvaziamento do campo e aumento do número de jovens camponeses que tornam-se trabalhadores assalariados, existe também uma resistência camponesa, inclusive por pessoas que mesmo não residindo mais no campo, tem a sua renda extraída do trabalho agrícola, como é o caso de camponeses do município de Itabaiana/SE. 
O munícipio de Itabaiana, está localizado na mesorregião do Agreste sergipano, sendo reconhecido como um "celeiro agrícola", apesar do destaque assumido também pela atividade comercial. Segundo Carvalho (1973, p.33) o itabaianense "se entregava de corpo e alma ao trabalho, isolando-se em seu sítio". Não obstante esse traço de forte base agrícola, o município se caracteriza como predominantemente urbano, pois $77 \%$ de sua população reside na cidade (IBGE, 2010), seguindo a lógica mundial de esvaziamento do campo.

No entanto, muitos dos camponeses que migram para a cidade não se desfazem de suas terras, e continuam a trabalhar em seus sítios. Estes, realizam uma migração diária, saindo da cidade para trabalhar no campo. Apesar de nas estatísticas constarem como moradores urbanos, é no campo que eles passam o dia inteiro e asseguram as condições para a reprodução social do trabalho eminentemente agrícola.

Isto posto, o objetivo deste artigo é analisar a mobilidade do trabalho camponês no munícipio de Itabaiana, representada pela migração pendular realizada por trabalhadores que residem na cidade, mas se deslocam diariamente para trabalhar em seus sítios, tendo a terra como condição de vida e garantia de reprodução social. A mobilidade do trabalho é uma característica do trabalhador sujeito ao capital, mas o sistema é formado por contradições, e no seu ímpeto por acumular ele mesmo dá as condições para a recriação das relações não capitalistas. Mesmo que a família camponesa não resida no campo, mas é a partir da mobilidade, que eles continuam reproduzindo seu modo de vida, que não é organizado pelas necessidades do mercado, e sim pelas necessidades de reprodução do grupo familiar (PAULINO; ALMEIDA, 2010).

O tema do texto emerge de uma proposta de dissertação que encontra-se em andamento, portanto as considerações expressas no texto ainda são preliminares. Como procedimentos metodológicos realizados destaca-se o levantamento bibliográfico e trabalhos de campo realizados no recorte da pesquisa de dissertação.

\section{A MOBILIDADE DO TRABALHO CAMPONÊS EM ITABAIANA}

A expropriação do camponês de sua base fundiária analisada por Marx (1985) no contexto da chamada acumulação primitiva, mostra-se relevante na compreensão dos processos atuais que dizem respeito à problemática e desafios enfrentados pelos camponeses. Nesse sentido, o desenraizamento e a destruição das relações sociais que não sejam relações 
capitalistas são essenciais no respectivo modo de produção. Ou seja, é a destruição das relações sociais tradicionais dos sujeitos em relação àquilo que eles eram e àquilo que eles estavam acostumados a ser, e assim "transformar as pessoas em produtores e consumidores de mercadorias, tudo tende a ser reduzido em mercadoria" (MARTINS, 2002, p.120). O que faz o capitalismo ao desenraizar as pessoas é transformá-las em proprietárias de uma única mercadoria: a sua força de trabalho. Dessa forma, a expropriação do camponês implica em reduzi-lo à única coisa que interessa, a condição de vendedor de sua força de trabalho.

Um dos rebatimentos desse processo é a mobilidade do trabalho compreendida como um fenômeno que promove o deslocamento espacial, setorial e profissional do trabalhador, com o objetivo do Capital explorar sua força de trabalho e acumular excedente econômico (GAUDEMAR, 1977). Dessa forma ela é introduzida em primeiro lugar, como a condição de exercício da liberdade do trabalhador de se deixar sujeitar ao Capital, de se tornar a mercadoria cujo consumo criará o valor e assim produzirá o Capital. É uma característica do trabalhador submetido ao Capital e por essa razão, do modo de produção capitalista. Ela funda a condição de exercício da força de trabalho como mercadoria, distinguindo assim definitivamente o trabalhador livre do escravo, cuja capacidade de trabalho é estável e só se emprega de maneira tradicional e local. A mobilidade é também a capacidade que permite à força de trabalho adaptar-se às variações da jornada de trabalho, a permutação dos postos de trabalho e aos efeitos de uma divisão do trabalho cada vez maior (GAUDEMAR, 1977).

No caso deste artigo analisamos a mobilidade do trabalho camponês no sentido inverso, visto que os camponeses migram para a cidade não somente seguindo uma lógica de que a cidade é o local que representa a modernização, mas impulsionados por condições adversas à permanência no campo como local de moradia ainda que continuem a trabalhar em seus sítios e retornem para a cidade no fim da tarde. Essa mobilidade pode ser vista, aparentemente, como o exercício da liberdade do trabalhador camponês, mas pode representar também uma resistência, pois há quem diga que o campo não oferece mais oportunidades de trabalho e reprodução social. Compreendemos a necessidade de observar e entender que existem diferenças fundamentais no processo de desenvolvimento do capitalismo. De acordo com Oliveira (2001, p. 18), "vamos encontrar no campo brasileiro, junto com o processo geral de desenvolvimento capitalista que se caracteriza pela implantação das relações de trabalho assalariado (...), a presença das relações de trabalho não capitalistas como, por exemplo: a parceria, o trabalho familiar camponês etc.". Esses trabalhadores se baseiam no trabalho não assalariado, o trabalho é familiar, traço fundamental do campesinato. 
Cabe a indagação registrada por Moura (1988, p.19) ao tratar da permanência do camponês diante da expansão do capitalismo no campo:

\begin{abstract}
Se, diferentemente dos demais meios de produção, a terra não é reprodutível, por que então o camponês permanece nela sem que a lógica capitalista demande sua completa expropriação? (...) Ocorre que o camponês desempenha um contraditório papel que, de um lado, expressa a sua resistência em desaparecer e, de outro é resultado do próprio capitalismo que não o extingue. Este não só extrai sobretrabalho dos operários, como também o capta onde é possível. Entre essas possibilidades encontrase o trabalho camponês. É nesse contexto de dramáticas tensões que o camponês vive no meio rural contemporâneo.
\end{abstract}

Itabaiana é um município que tem sua estrutura fundiária formada por pequenas propriedades. É muito comum que as pessoas se refiram a essas propriedades como "sítio". Existem vários tipos de sítio, sendo os mais comuns compostos das seguintes partes: a malhada/roça, o pasto, a casa de farinha (atualmente nem todos os sítios possuem), a casa e o quintal. No entanto, nem todos os sítios possuem malhadas, assim como nem todos possuem a roça (WOORTMAM, 1983). Muitos dos camponeses que migram para a cidade não se desfazem de suas terras/sítios, e continuam a trabalhar em suas malhadas. Estes, realizam uma migração diária, saindo da cidade para trabalhar no campo.

Observa-se que as terras no município de Itabaiana estão sofrendo uma alta especulação fundiária causada principalmente pelo avanço dos loteamentos imobiliários em áreas ocupadas anteriormente por estábulos e pequenos sítios. Ademais, passam por um processo de valorização que pode ser identificado a uma renda diferencial analisada por Marx (2017). O autor considera a presença da Renda Diferencial I e Renda Diferencial II. A primeira está relacionada à produtividade dos solos e a sua localização, quando próximos a perímetros irrigados, rios, açudes, e fácil acesso à cidade. E na renda diferencial II, ao investimento fixado na propriedade, como exemplo, os poços artesianos.

Com a crescente especulação das terras, valorizadas pela proximidade da cidade, muitos camponeses acabam vendendo suas terras e indo morar na cidade, o que geralmente ocorre quando adquirem a aposentadoria. Mas muitos dos que vão morar na cidade não se desfazem das terras e acabam indo por causa dos filhos que precisam estudar, ou até mesmo trabalhar na cidade, dado os tamanhos das propriedades serem pequenas e não possibilitar que os filhos tenham a sua própria terra. Os pais, como não possuem outro emprego, permanecem trabalhando no campo. 
O fato do camponês continuar possuindo seu próprio meio de produção, que é a terra, num momento de alta especulação fundiária, constitui-se uma resistência ao capital, haja vista que o ponto de partida do desenvolvimento do capitalismo foi a acumulação primitiva, que separou o produtor do seu meio de produção. Os camponeses foram expropriados, e assim conquistaram o campo para a agricultura capitalista, incorporando a base fundiária ao Capital (MARX, 2017).

\title{
RESISTÊNCIA CAMPONESA
}

Analisamos a mobilidade dos camponeses ao retornar para trabalhar nos sítios como uma alternativa de reprodução social, constatando que o campesinato resiste, ainda que se molde à lógica capitalista. Entendemos o campesinato como uma classe social e não apenas como um setor da economia, uma forma de organização da produção ou um modo de vida. Como analisa Marques (2008, p. 65):

\begin{abstract}
O camponês brasileiro é um migrante e sua expropriação não tem representado uma ruptura total de seus vínculos com a terra. A maioria deles mantém alguma relação com o campo, seja ela mais próxima ou mais distante - relação direta de trabalho, vínculos familiares, relação de origem etc. O que explica, em parte, a permanência entre eles de um conjunto de símbolos e valores que remetem a uma ordem moral ou lógica tradicional e a possibilidade de o acesso à terra se apresentar como uma alternativa para pobres do campo e da cidade que buscam assegurar a sua sobrevivência mantendo a dignidade de trabalhador.
\end{abstract}

Segundo Shanin (2005, p. 9), o campesinato é, ao mesmo tempo, uma classe social e um "mundo diferente", que apresenta padrões de relações sociais distintos - ou seja, o que também podemos denominar de modo de vida. E analisa que:

Sob certas condições, os camponeses não se dissolvem, nem se diferenciam em empresários capitalistas e trabalhadores assalariados, e tampouco são simplesmente pauperizados. Eles persistem, ao mesmo tempo em que se transformam e se vinculam gradualmente à economia capitalista, que pervade suas vidas. Os camponeses continuam a existir, correspondendo a unidades agrícolas diferentes em estrutura e tamanho. À medida que o capitalismo avança, os camponeses são marginalizados, a importância da agricultura camponesa dentro da economia nacional é desconsiderada, o crescimento mais lento de sua produção torna-a atrasada. 
O sistema faz com que o camponês precise se vincular a economia capitalista, seja por meio do uso de agrotóxicos para acelerar sua produção, ou por meio de empréstimos para que possa se "modernizar" e tentar corresponder à imposição da competitividade. Entretanto a inserção do camponês no mercado representa uma lógica diferenciada do caráter capitalista, expressa na fórmula M-D-M (mercadoria-dinheiro-mercadoria) ao contrário da produção capitalista que é representada por D-M-D (OLIVEIRA, 2007). Ou seja, as mercadorias produzidas pelos camponeses são vendidas para conseguir o dinheiro para comprar as mercadorias que eles não produzem. Sua relação com o capital não se dá por meio da exploração direta de seu trabalho pelo capitalista. A exploração de seu trabalho aparece ocultada na extração de renda fundiária, aparece sob a forma de pagamento de renda da terra. Isso não quer dizer que não exista no campo o operário agrícola, o assalariado, esse sim, se defronta diretamente com o capital que utiliza e explora seu trabalho (MARTINS, 2002).

Uma das principais características do campesinato é a liberdade, mas para diferenciar a liberdade camponesa da discussão burguesa do ser livre, é necessário destacar que a desigualdade é produto do sistema social e tem sua origem determinada pela riqueza, o nível econômico, o que quer dizer a propriedade privada de cada um (PAULINO; ALMEIDA, 2010). Entretanto não é qualquer propriedade que possibilita riqueza, mas sim aquela que gera acumulação capitalista.

Considerando o campesinato como uma relação não capitalista e a propriedade familiar camponesa como instrumento de vida de trabalho, não de acumulação/reprodução do capital, podemos afirmar que para o camponês a detenção da propriedade privada familiar da terra não figura como representação mental da desigualdade entre os indivíduos. A liberdade tem relação com a autonomia no sentido do controle do tempo de trabalho, situação que por sua vez é proporcionada pelo fato de ser dono da terra, ao contrário do empregado (PAULINO; ALMEIDA, 2010).

A terra é a unidade camponesa, o sítio, que ao contrário da propriedade capitalista que serve para explorar o trabalho alheio, é vista como a propriedade direta dos instrumentos de trabalho, que pertencem ao próprio trabalhador, a terra de trabalho. E mesmo que eles não morem mais nesse sítio, não se desfazem da terra, pois ela continua sendo a garantia de sua reprodução.

Pelo fato da produção camponesa possuir características próprias, como o trabalho familiar, a produção de policulturas e produtos de subsistência e ter um ritmo mais lento já que se baseia na produção familiar, sem exploração de força de trabalho, surgem os discursos de 
que o campo e o modo de vida deles são sinônimos de atraso, e que não há possibilidade de sobrevivência, pois não há como obter lucro. Discursos estes por vezes reproduzidos pelos próprios camponeses, a partir de uma construção ideológica que gradativamente foi imposta e assimilada pela maioria, desapercebida de que a "modernização" produz riqueza para poucos e pobreza para muitos e, por conseguinte, intensifica as múltiplas desigualdades socioespaciais (CAMPOS, 2011).

\section{CONSIDERAÇÕES FINAIS}

A constituição de 1934 que definiu uma legislação trabalhista para o país - salário mínimo, descanso semanal e férias remuneradas, 8 horas de trabalho diário, previdência social - não se estendeu ao campo. Nesta ocasião, a inserção no mundo do trabalho formal passou a representar o principal meio de acesso à cidadania.

Na medida em que a legislação trabalhista não se estende ao campo, a cidade a ele se opõe como o espaço da cidadania. Migrar para a cidade passa a representar, então, uma maneira de ampliação das possibilidades de entrar no mundo do direito (MARQUES, 2006). Nesse sentido, o Estado representa o principal agente das mudanças para atender às exigências de um modelo de desenvolvimento, assentado no discurso da modernização o que resultou em considerável êxodo rural e intensificação da mobilidade do trabalho (CONCEIÇÃO, 2013).

A redistribuição espacial de nossa população, que, de modo geral, acompanhou a dinâmica do mercado de trabalho, tem obedecido a outros padrões nos últimos anos. As grandes cidades reduziram seu ritmo de crescimento devido à redução brutal das oportunidades de emprego nestas cidades. Por outro lado, são estabelecidos fluxos de retorno de regiões mais ricas para regiões mais pobres. Entre outros fatores que explicam este processo, não se pode esquecer a cultura de sobrevivência, que, em momentos de crise aguda, impõe a opção pelo lugar mais conhecido, onde se conta com uma rede de relações já estabelecida (MARQUES, 2006).

E o campesinato é uma classe que tem muito a nos ensinar sobre como enfrentar os períodos de crise, como afirma Shanin, (2008, p. 25-26): 
o problema de como ganhar a vida, são qualidades encontradas em todos os camponeses que sobrevivem as crises.

Independentemente de sua inserção no mundo da mercadoria, o camponês está voltado para o pequeno mundo concreto que conhece e se identifica. Como a família e o povoado, isto é, a vizinhança e a comunidade. Mesmo definitivamente na cidade e fora da agricultura, quem saiu do mundo rural continua por longo período mantendo essas referências sociais. São relações de reciprocidade, motivadas por uma orientação social básica que tem o outro como referência (MARTINS, 2002).

Consideramos que para a existência do campesinato a terra é fundamental, haja vista ser ela a fonte de reprodução da própria condição de existência, mesmo que os camponeses não mais residam nos sítios e/ou malhadas, mas ainda assim a têm como garantia de vida e reprodução social. O que se tem visto é que o modo de vida camponês resiste e sobrevive em muitos contextos espaciais rurais estendendo-se até as cidades. É um modo de vida considerado como sendo de "resistência" das populações e comunidades rurais frente ao avanço da especulação fundiária evidenciada na pesquisa empírica.

\section{AGRADECIMENTOS}

Este trabalho foi desenvolvido com o apoio financeiro da CAPES, com a bolsa de pesquisa de Mestrado.

\section{REFERÊNCIAS}

CAMPOS, Christiane Senhorinha Soares. A territorialização do agronegócio no Brasil. p. 101 132. In: CAMPOS, Christiane Senhorinha Soares. A face feminina da pobreza em meio a riqueza do agronegócio: trabalho e pobreza das mulheres em territórios do agronegócio no Brasil: o caso de cruz alta/RS. 1 ed. Buenos Aires: Clacso, 2011. 208p.

CONCEIÇÃO, Alexandrina Luz. Estado, Capital, Trabalho e a farsa da expansão do agronegócio. Geografia Meridiano, n. 2, 2013.

CARVALHO, Vladimir Souza. Santas Almas de Itabaiana Grande. Itabaiana: edições “o serrano", 1973. Disponível em: <www.guiadeitabaiana.com.br/artigos> acesso em: 19 de jul. 2016.

DELGADO, Guilherme. O capital financeiro e agricultura no Brasil - 1965-1985. São Paulo, ed. Ícone, 1985.

GAUDEMAR, Jean Paul. Mobilidade do Trabalho e Acumulação do Capital. Trad. Maria do Rosário Quintela. Lisboa: editora Estampa, 1977. 
JAKIMIU, Camila Campos de Lara; GEMELLI, Diane Daniela. Mobilidade Territorial do trabalho expressa na relação campo-cidade no munícipio de União da Vitória-PR geografia Opportuno Tempore. Londrina, v.1, n.4, p. 59-69, 2015.

MARQUES, Marta Inez Medeiros. Entre o campo e a cidade: formação e reprodução social da classe trabalhadora brasileira. Agrária. São Paulo, N 5, p.170-185, 2006.

A atualidade do uso do conceito de camponês. REVISTA NERA. Presidente Prudente, 2008. P. 57-67. Ano 11, n. 12 - janeiro/junho de 2008 - ISSN: 1806-6755

MARTINS, José de Souza. A sociedade Vista do Abismo: novos estudos sobre exclusão, pobreza, e classes sociais. Petrópolis: Editora Vozes, 2002.

MARX, Karl. O Capital crítica da Economia Política livro III: o processo global da produção capitalista. Trad. Rubens Enderle; edição de Friedrich Engels. 1.ed. São Paulo: Boitempo, 2017. $977 \mathrm{p}$.

O capital. Crítica à economia política. Vol. I Livro primeiro. O processo de produção do capital. São Paulo: nova cultural, 1985.

MOURA, Margarida Maria. Camponeses. 2. Ed. São Paulo: Ática, 1988.

OLIVEIRA, Ariovaldo Umbelino. A agricultura camponesa no Brasil. São Paulo: contexto, 2001.

OLIVEIRA, Francisco de. Crítica a razão dualista: o ornitorrinco. Boitempo editorial: São Paulo, 2003.

PAULINO, Eliane Tomiasi; ALMEIDA, Rosemeire Aparecida de. Terra e território: A questão camponesa no capitalismo. São Paulo: Expressão Popular, 2010. 1 ed. 112p.

SHANIN, Teodor. A definição de camponês: conceituações e desconceituações - o velho e o novo em uma discussão marxista. Revista Nera - Ano 8, N. 7 - Julho/Dezembro De 2005 Issn 1806-6755

Lições camponesas. In: PAULINO, Eliani Tomiasi; FABRINI, João E. (orgs). Campesinato e territórios em disputa. São Paulo: Expressão Popular, 2008, p.23-47.

WOORTMAM, Ellen F. O Sítio Camponês. Anuário Antropológico. n. 81, p. 164-203. 1983. Disponível em: < http://www.dan.hospedagemdesites.ws/anuario-antropologico-listagemdosnumeros/138-anuario-antropologico-sumario-1981> Acesso em 25 de jan. 2018.

WOORTMAM, Klass. "Com Parente não se Neguceia” O campesinato Como Ordem Moral. Anuário antropológico. n.87. Editora Universidade de Brasília/tempo brasileiro. 1990. Disponível em: <https://pt.scribd.com/document/318498675/Com-parente-nao-se-neguceiaIn-AnuarioAntropologico-WOORTMANN-K-pdf> Acesso em: 25 de jan. 2018. 